\title{
Patient and health care system characteristics are associated with delayed treatment of tuberculosis cases in Taiwan
}

\author{
Chien-Chou Chen ${ }^{1}$, Po-Huang Chiang ${ }^{2}$, Yen-Hsu Chen ${ }^{3,4,5,9^{*}}$, I-Chun Fan ${ }^{6,7}$ and Ta-Chien Chan ${ }^{7,8^{*}}$ (D)
}

\begin{abstract}
Background: The decline of the incidence rate of tuberculosis in Taiwan has been partly attributed to the launch of the directly observed therapy short course (DOTS) program in 2006, followed by the DOTS-Plus in 2007. However, with the phasing out of the specialized tuberculosis care system and the declining incidence, clinical workers in Taiwan might become less familiar with the presentation of tuberculosis. Complementing the patientpathway analysis with health system delay estimates, the objective of this study is twofold: to estimate the alignment between patient care initiation and the availability of prompt diagnostic and treatment services, and to identify the risk factors of delayed tuberculosis treatment.
\end{abstract}

Methods: The study population included all Taiwanese patients with incident tuberculosis in 2013. We (1) identified 11,507 incident tuberculosis patients from the 2013 National TB Registry, and (2) linked 10,932 Taiwanese from the registry to the 2012-2013 National Health Insurance Research Database. We assessed patient's care-seeking pathways and associated the determinants of health system delay in a Cox model.

Results: The overall health system delay was 46 days. We found that 20.5 and $3.5 \%$ of 10,932 tuberculosis patients were diagnosed and treated respectively at the initial visit to seek care for TB-related symptoms. Risk factors related to the prolonged health system delay included female gender (adjusted $\mathrm{HR}=0.921,95 \% \mathrm{Cl}$ : 0.884, 0.960), age $>=$ 65 years (adjusted $\mathrm{HR}=0.720,95 \% \mathrm{Cl}: 0.692,0.750$ ), non-severe (chest $X$-ray without cavities) (adjusted HR $=0.721$, 95\% Cl 0.683-0.760), chronic respiratory diseases (adjusted HR=0.544, 95\% Cl: 0.522, 0.566), living in long-term care facilities (adjusted $\mathrm{HR}=0.580,95 \% \mathrm{Cl}: 0.525,0.640$ ), an initial visit at a primary care clinic (adjusted $\mathrm{HR}=0.588,95 \% \mathrm{Cl}$ : $0.565,0.612$ ), and living in southern Taiwan (adjusted HR=0.887, 95\% Cl: $0.798,0.987$ ).

Conclusions: The low access to TB diagnostic and treatment services at the initial visit and the prolonged health system delay indicate inefficiency in the health care system. Strengthening training of physicians at public hospitals and health workers at nursing homes might improve the efficiency and timeliness of tuberculosis diagnosis and treatment in Taiwan.

Keywords: Tuberculosis, Patient-pathway analysis, Health system delay

\section{Background}

Since the health sector reform in 2002, Taiwan has integrated the previous vertical tuberculosis (TB) control system into the general health care system [1]. The incidence rate of TB has gradually decreased from 63.2 (per 100,000 people) in 2007 to 45.7 in 2015 [2]. The declining incidence

\footnotetext{
* Correspondence: infchen@gmail.com; dachianpig@gmail.com

${ }^{3}$ Department of Internal Medicine, Kaohsiung Municipal Ta-Tung Hospital, Kaohsiung, Taiwan

${ }^{7}$ Research Center for Humanities and Social Sciences, Academia Sinica, Taipei, Taiwan

Full list of author information is available at the end of the article
}

rate has been partly attributed to the launch of the directly observed therapy short course (DOTS) program in 2006, followed by the DOTS-Plus for multidrug-resistant TB in 2007 , preventing the spread of TB bacilli $[3,4]$. Recently, a new regimen of 3 months of isonianizid plus rifapentine for latent TB infection (LTBI) has been introduced into Taiwan, contributing to the ongoing eradication of TB [5]. However, TB incidence in 2007-2015, portrayed by a ring map (Fig. 1), was heterogeneous at the city and county levels.

With the phasing out of the specialized TB care system and the declining TB incidence, it is likely that more 


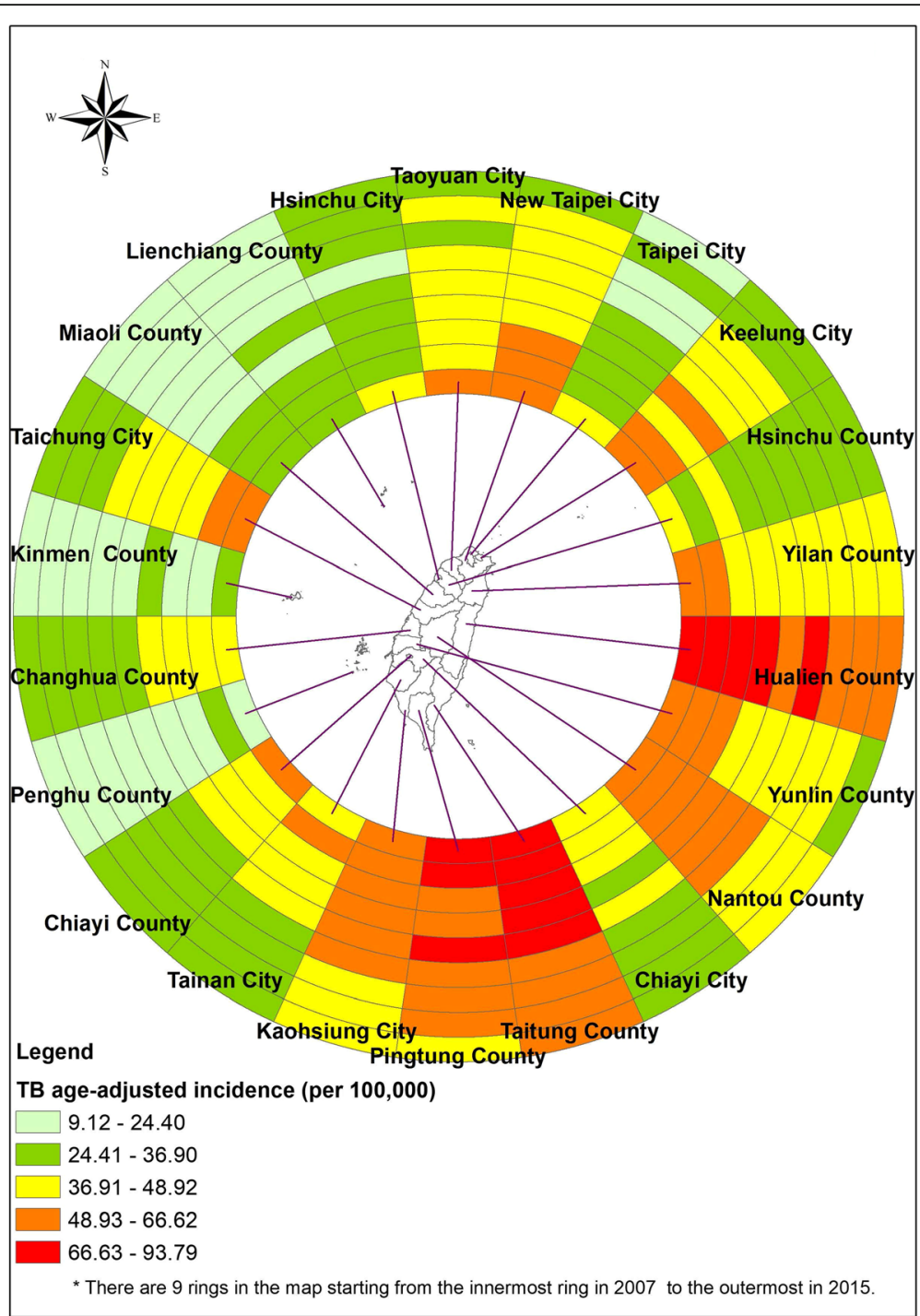

Fig. 1 Tuberculosis incidence rates in Taiwan. The map presents tuberculosis incidence in a compelling manner by year (2007-2015 from inner to outer rings) and region $(n=22)$

clinical workers will become less familiar with the presentation of TB [1]. Meanwhile, if the general health care system is not efficient in promptly identifying patients with $\mathrm{TB}$, the patients might need to make repeated visits within the health care system for a prolonged period before being diagnosed with TB [6]. It is even worse that frequent health care visits of nontuberculous patients appear to be a risk factor for contracting TB $[7,8]$.

The objective of the study is twofold: to estimate the gap between care initiation and availability of TB services, and to identify the risk factors of delayed TB treatment. A patient-pathway analysis (PPA) assesses the alignment between patient care initiation and the availability of prompt $\mathrm{TB}$ diagnostic and treatment services [9-13]. In addition, health system delay [14, 15] (HSD) analysis measures the delay between the initial visit to seek care for TB-related symptoms and the initiation of TB treatment. Complementing PPA with HSD estimates, our assessment addresses the amount of access to TB services and further unveils the determinants of delay. Furthermore, the sector effect (public against private) and health facility type (hospital against primary care clinic) on TB services are also revealed [16]. The results might guide prioritization of regions or hospitals for intensified engagement in the general health care system.

\section{Methods}

Ethics

This study was approved by the institutional review board (IRB) of Kaohsiung Medical University Chung-Ho 
Memorial Hospital for research ethics (IRB\#: KMUHIRBSV (I)-20,160,057). The data used in this study were derived from linkage of two databases including the National Health Insurance Research Database (NHIRD) and the TB registry. Trained staff from the Health and Welfare Data Science Center, Ministry of Health and Welfare, Taiwan conducted the procedures of data linkage and scrambled personal identification. Based on their regulation, researchers can only take out summarized statistical results, without any raw data. In addition, the data were all analyzed anonymously. Therefore, we did not need to get consent from each patient.

\section{Study population}

The study population included all 11,507 patients with incident TB from the 2013 TB registry. Pulmonary TB diagnosis in Taiwan is based on clinical diagnosis, chest $\mathrm{X}$-ray, sputum smear, and mycobacterium culture. The criteria of a confirmed case include a positive sputum smear/culture or clinical information, and the cases were approved by the government's Center of Disease Control [17]. We excluded 535 patients due to important missing variables like results of sputum smear and culture. To analyze the care-seeking pathway of patients, we linked medical claim records from the 2012-2013 NHIRD to 10,932 Taiwanese in the TB registry (Fig. 2). NHIRD contains all the registration and claims data including utilization of inpatient and outpatient services for around 23,000,000 Taiwanese [18]. The coverage of
NHIRD is more than $98 \%$ of the total population [19]. Under the coverage of universal health insurance, patients are free to seek health services from any clinician. A referral system is established, but tiered referral procedures are not mandatory [20]. Patients who prefer to directly visit tertiary care hospitals can do so without any referral, even for simple illnesses such as upper respiratory infection [20].

\section{Operational definitions}

HSD is defined as the interval between the first medical consultation for respiratory-related diseases and the initiation of TB treatment (Fig. 2) [1]. To identify the first medical consultation of a TB patient from NHIRD, two sequential respiratory-related visits were treated as belonging to the same respiratory episode if the interval between the two visits was $\leq 60$ days, and as different respiratory episodes if the interval was $>60$ days [21]. The observation window for measuring HSD was 12 months before the start of TB treatment. Details on identifying the initial visit from NHIRD were described in our previous study [21]. Dates of TB diagnosis and treatment were defined by the $2013 \mathrm{~TB}$ registry. Chronic respiratory patients were patients who (1) took refillable chronic respiratory medicines for $\geqq 28$ days; or (2) took at least one respiratory medicine for $\geqq 28$ days; or (3) were recorded as having chronic respiratory diseases in NHIRD during the one-year observation window (Additional file 1: Table S1) [21]. Patients whose medical claims

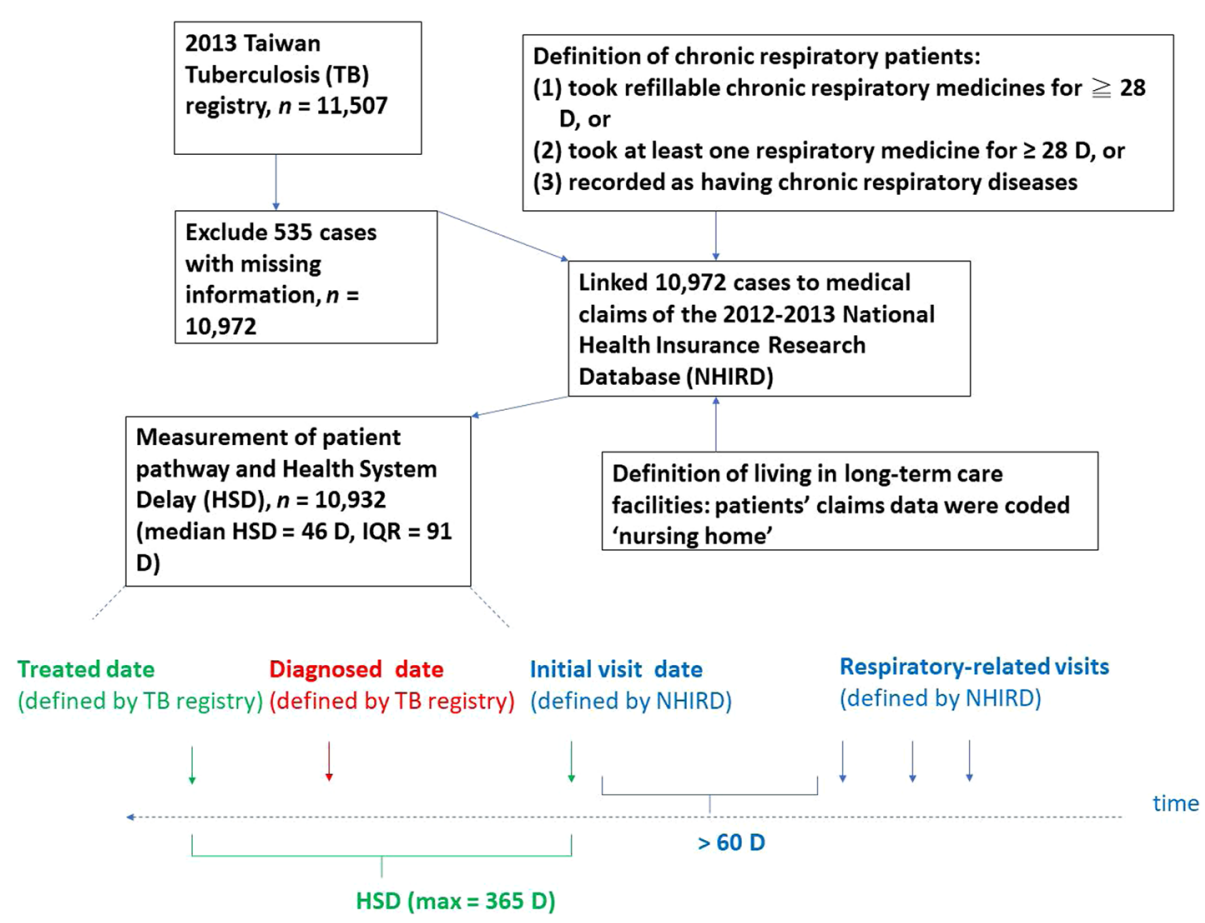

Fig. 2 Flowchart of the study 
were coded 'nursing home' were recognized as living in long-term care facilities (Fig. 2).

\section{Health system delay and patient-pathway analyses}

We treated HSD as time to event (treatment) data and investigated the HSD determinants by using a survival analysis. Cox proportional hazards regression was used to estimate the hazard ratios (HRs) of determinants in both univariable and multivariable models [22]. An $\mathrm{HR}<1$ indicated that the determinant was associated with a longer HSD and vice versa. We used SAS 9.3 (SAS Institute Inc., Cary, NC, USA) to perform the statistical analysis.

We further examined a patient's care-seeking pathways from the first medical consultation to the initiation of TB treatment (Fig. 2). We marked the patient's visits in chronological sequence and evaluated whether TB services (diagnosis and treatment) were provided on the date of initial visit. If a patient's earliest date of TB diagnostic test (treatment) in the TB registry was on or before the initial visit date (treatment initiation date) in NHIRD, TB diagnosis (treatment) was provided. For those whose HSD was 0, TB treatment was provided at the initial visit.

\section{Results}

In this cross-sectional study, incident cases from the 2013 TB registry were linked to the 2012-2013 NHIRD to conduct patient-pathway and HSD analyses (Fig. 2). Seventy percent of the total of 10,932 incident TB patients were male (Table 1). More than half of the patients (52.5\%) were aged $\geqq 65$ years. Percentages of abnormal X-ray, initial sputum smear-positive, and initial culture-positive were 91.0, 30.0, and 63.3\%, respectively.

For patients with chronic respiratory diseases (39.2\% of 10,932), median HSD was significantly longer than for those without (78 days against 32 days). Patients living in long-term care facilities $(3.8 \%$ of 10,932$)$ had a dramatically longer delay (median $\mathrm{HSD}=140$ days) than others $($ median $=44$ days $)$. Compared to patients whose initial visits were at a hospital (median HSD $=33$ days), patients whose initial visits were at a primary care clinic suffered from prolonged HSD (median HSD $=68$ days). In terms of area, median HSD ranged from 41 to 49 days in six administrative districts of Taiwan. The overall HSD was 46 days (interquartile range $=91$ days).

We depicted the percentages of access to TB diagnostic and treatment services at the time of initial visit by 22

Table 1 Characteristics of incident tuberculosis patients from the 2013 tuberculosis registry, Taiwan $(n=10,932)$

\begin{tabular}{|c|c|c|c|c|c|}
\hline Variable & & $N(\%)$ & Median HSD $\left(\mathrm{IQR}^{\mathrm{b}}\right)$ & Median two-sample test & $p$-value \\
\hline \multirow[t]{2}{*}{ Gender } & Male & $7652(70.0)$ & $44(89)$ & 3.197 & 0.001 \\
\hline & Female & $3280(30.0)$ & $49(90)$ & & \\
\hline \multirow[t]{2}{*}{ Age } & $<65$ & $5223(47.8)$ & $33(65)$ & -18.925 & $<0.001$ \\
\hline & $>=65$ & $5709(52.5)$ & $60(121)$ & & \\
\hline \multirow[t]{2}{*}{ Chest X-ray abnormal } & Yes & 9949 (91.0) & $45(90)$ & 1.916 & 0.056 \\
\hline & No & $983(9.0)$ & $49(93)$ & & \\
\hline \multirow[t]{2}{*}{ Sputum smear-positive (1st sample) } & Yes & $3279(30.0)$ & $34(94)$ & -7.759 & $<0.001$ \\
\hline & No & $7653(70.0)$ & $49(87)$ & & \\
\hline \multirow[t]{2}{*}{ Sputum culture-positive (1st sample) } & Yes & $6919(63.3)$ & $45(93)$ & 0.424 & 0.671 \\
\hline & No & $4013(36.7)$ & $46(86)$ & & \\
\hline \multirow[t]{2}{*}{ Chronic respiratory patient } & Yes & $4282(39.2)$ & $78(160)$ & 28.908 & $<0.001$ \\
\hline & No & $6650(60.8)$ & $32(60)$ & & \\
\hline \multirow[t]{2}{*}{ Long-term care facilities } & Yes & $420(3.8)$ & $140(272)$ & 12.202 & $<0.001$ \\
\hline & No & $10,512(96.2)$ & $44(85)$ & & \\
\hline \multirow[t]{2}{*}{ Health facility type of initial visit } & Primary care clinic & 4319 (39.5) & $68(110)$ & 25.339 & $<0.001$ \\
\hline & Hospital & $6613(60.5)$ & $33(71)$ & & \\
\hline \multirow[t]{6}{*}{ District of initial visit } & Eastern (reference) & 429 (3.9) & $41(94)$ & 9.006 (ChiSq) & 0.109 \\
\hline & Taipei & $3090(28.3)$ & $45(84)$ & & \\
\hline & Northern & $1301(11.9)$ & $42(82)$ & & \\
\hline & Central & 2029 (18.6) & $45(91)$ & & \\
\hline & Southern & $1695(15.5)$ & $49(101)$ & & \\
\hline & KaoPing & $2388(21.8)$ & $47(96)$ & & \\
\hline
\end{tabular}


regions (cities and counties) (Fig. 3). Sixty percent of TB patients initiated their care visits at hospital (Table 1). Overall, the percentages of access to TB diagnostic and treatment services at the initial visit were $20.5 \%(2244 / 10,932)$ and $3.5 \%(380 / 10,932)$, respectively at the national level. In regions with more incident TB cases, lower percentages of patients received TB services at the initial visit. For example, $16.7 \%(n=313)$ and $2.9 \%(n=55)$ of patients received TB diagnosis and treatment at the initial visit in New Taipei City (total cases $=1887$ in 2013) compared to $25.2 \%(n=44)$ and $4.6 \%(n=8)$ in Taitung County (total cases $=173$ in 2013) [23].

Among those receiving TB diagnosis $(n=2244)$ and treatment $(n=380)$ at the initial visit, we further examined what types of health facility (private clinic, private hospital, public clinic, and public hospital) they visited. We observed that hospitals (green colors) had a higher share than primary care clinics (red colors) across all regions except Taitung County (Fig. 4). Distributions for the percentage of TB treatment at the initial visit are similar to the pattern in Fig. 4, and even magnified (Fig. 5) where the share of private hospitals (dark green) becomes more dominant in a trend test $(p$-value $<0.001)$.

We portray the estimates of Cox proportional hazard model in Table 2 and Additional file 2: Figure S1. The median HSD differed by gender, age, severity, whether they also had chronic respiratory diseases, whether living in long-term care facilities, health facility type, and administrative district. In the multivariable survival analysis, patient's risk factors for prolonged HSD included: female (adjusted $\mathrm{HR}=0.921,95 \%$ confidence interval $[\mathrm{CI}]: 0.884,0.960)$ as compared to males; aged ( $\geqq 65$ years) (adjusted $\mathrm{HR}=0.720,95 \% \mathrm{CI}: 0.692,0.750$ ) as compared to young patients (aged < 65 years old); nonsevere (adjusted HR $=0.721,95 \%$ CI $0.683-0.760$ ) as compared to severe (chest X-ray with cavities), and patients with chronic respiratory diseases (adjusted HR = 0.544, 95\% CI: 0.522, 0.566). Health-system-related risk factors were: patients living in long-term care facilities (adjusted HR $=0.580,95 \% \mathrm{CI}: 0.525,0.640$ ); an initial visit to a primary care clinic (adjusted HR $=0.588,95 \%$ CI: $0.565,0.612$ ) as compared to a hospital, and southern (adjusted HR $=0.887,95 \%$ CI: 0.798, 0.987) as compared to eastern Taiwan.

\section{Discussion}

Patient-pathway and HSD analyses were conducted to unveil the alignment between patient care seeking and the availability of prompt TB services among 10,932 incident cases in Taiwan. The results suggest that 20.5 and $3.5 \%$ of TB patients were diagnosed and treated at the initial visit in Taiwan. Risk factors related to prolonged HSD included female gender, aged $>=65$ years, nonsevere (chest X-ray without cavities), having chronic respiratory diseases, living in long-term care facilities, an

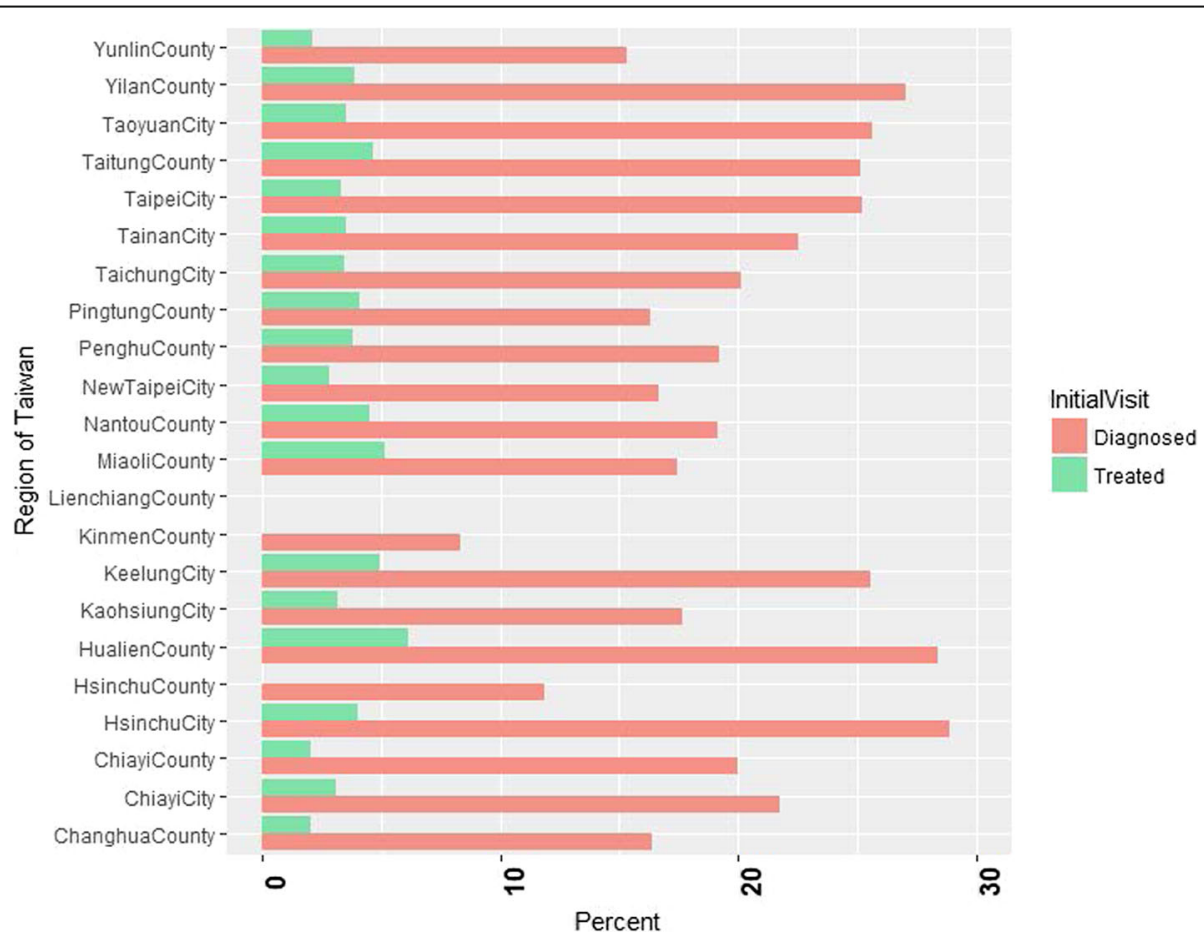

Fig. 3 Percent of access to tuberculosis diagnostic and treatment services at the initial care seeking by region. Note that the percentages for access to tuberculosis diagnostic and treatment services at the initial visit are 0 in Lien-chiang County 


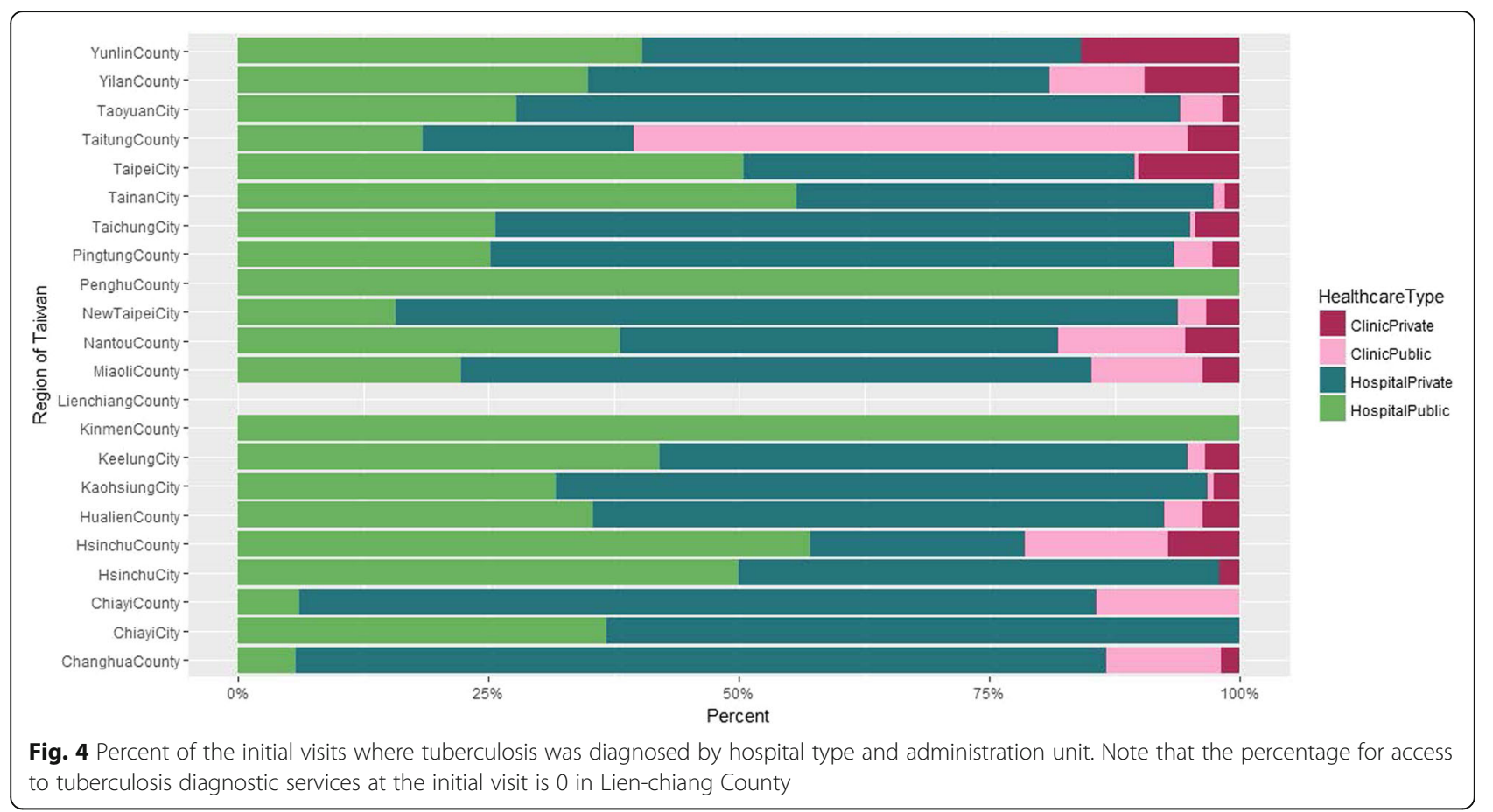

initial visit to a primary care clinic, and southern areas of Taiwan.

Although approximately $60.5 \%$ of patients initiated care seeking at a hospital, HSD (median $=46$ days) remains long compared with other countries (for example, median HSD $=15$ days in Croatia) with an intermediate TB disease burden [24]. The low access to TB diagnosis
(20.5\%) and treatment (3.5\%) at the initial visit indicates inefficiency in Taiwan's health system. We also observed regional differences in access to $\mathrm{TB}$ services. For example, a relatively low percentage of prompt TB diagnosis and treatment at the initial visit and prolonged HSD in southern areas might require further examination. On the other hand, strengthening physician training at

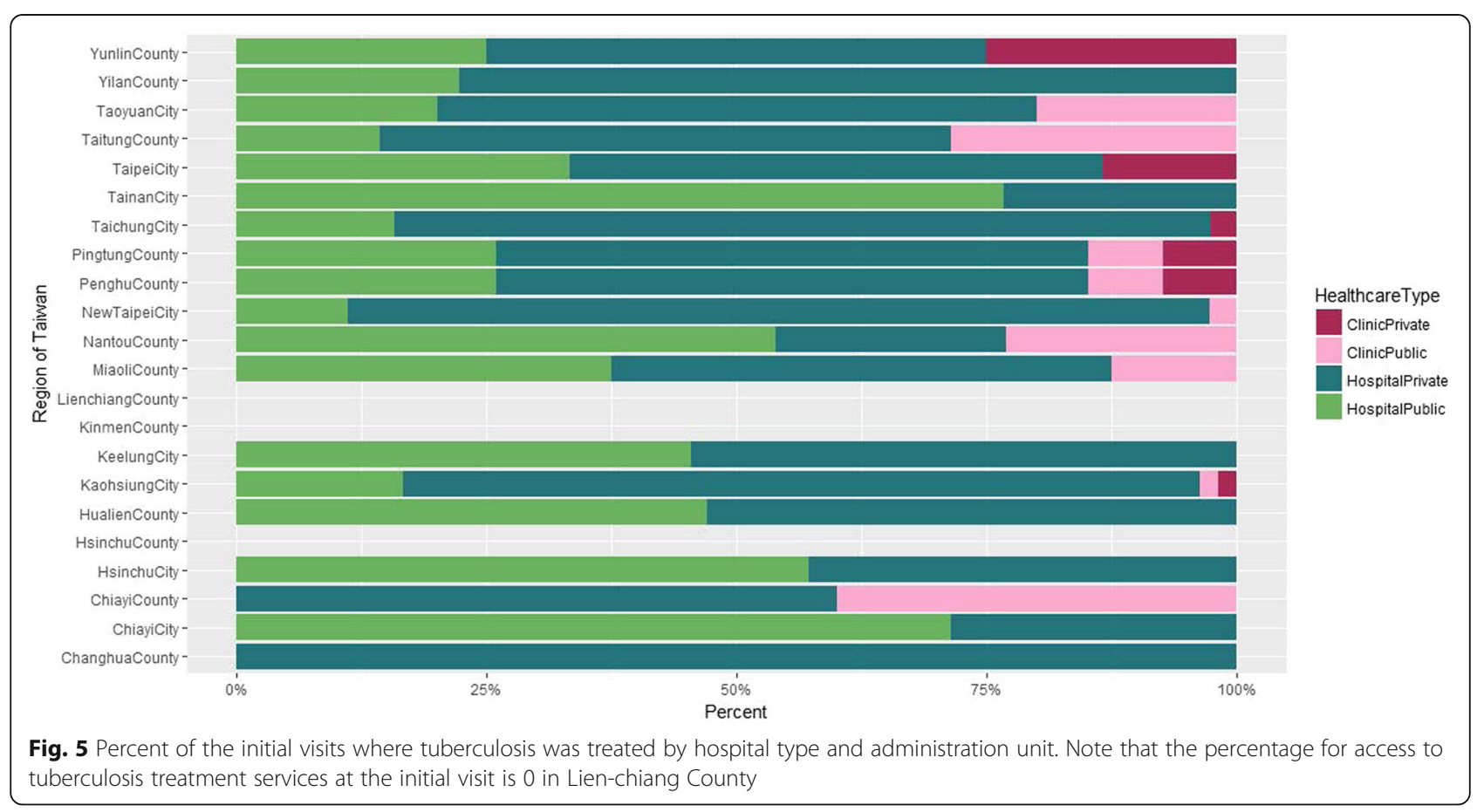


Table 2 Cox proportional hazard model on health system delay (HSD) for incident tuberculosis patients in Taiwan, 2013 ( $n=10,932)$

\begin{tabular}{|c|c|c|c|c|c|c|}
\hline \multirow[t]{2}{*}{ Variable } & \multicolumn{3}{|l|}{ Crude } & \multicolumn{3}{|l|}{ Adjusted } \\
\hline & Parameter (SD) & Hazard ratio $(\mathrm{Cl})$ & $p$-value & Parameter (SD) & Hazard ratio $(\mathrm{Cl})$ & $p$-value \\
\hline $\begin{array}{l}\text { Female (against male) } \\
(n=3280)\end{array}$ & $\begin{array}{l}-0.040 \\
(0.020)\end{array}$ & $\begin{array}{l}0.961 \\
(0.922,1.001)\end{array}$ & 0.053 & $\begin{array}{l}-0.081 \\
(0.021)\end{array}$ & $\begin{array}{l}0.921 \\
(0.884,0.960)\end{array}$ & $<0.001$ \\
\hline Age $>=65$ years (against age $<65$ years) $(n=5709)$ & $\begin{array}{l}-0.456 \\
(0.019)\end{array}$ & $\begin{array}{l}0.634 \\
(0.610,0.658)\end{array}$ & $<0.001$ & $\begin{array}{l}-0.328 \\
(0.020)\end{array}$ & $\begin{array}{l}0.720 \\
(0.692,0.750)\end{array}$ & $<0.001$ \\
\hline Non-severe (against chest X-ray with cavities) $(n=9297)$ & $\begin{array}{l}-0.356 \\
(0.026)\end{array}$ & $\begin{array}{l}0.700 \\
(0.664,0.733)\end{array}$ & $<0.001$ & $\begin{array}{l}-0.327 \\
(0.027)\end{array}$ & $\begin{array}{l}0.721 \\
(0.683,0.760)\end{array}$ & $<0.001$ \\
\hline $\begin{array}{l}\text { Patients with chronic respiratory diseases } \\
(n=4282)\end{array}$ & $\begin{array}{l}-0.664 \\
(0.020)\end{array}$ & $\begin{array}{l}0.514 \\
(0.494,0.535)\end{array}$ & $<0.001$ & $\begin{array}{l}-0.609 \\
(0.020)\end{array}$ & $\begin{array}{l}0.544 \\
(0.522,0.566)\end{array}$ & $<0.001$ \\
\hline Long-term care facilities $(n=420)$ & $\begin{array}{l}-0.615 \\
(0.049)\end{array}$ & $\begin{array}{l}0.540 \\
(0.490,0.596)\end{array}$ & $<0.001$ & $\begin{array}{l}-0.544 \\
(0.050)\end{array}$ & $\begin{array}{l}0.580 \\
(0.525,0.640)\end{array}$ & $<0.001$ \\
\hline $\begin{array}{l}\text { Primary care clinic } \\
(n=4319)\end{array}$ & $\begin{array}{l}-0.399 \\
(0.019)\end{array}$ & $\begin{array}{l}0.671 \\
(0.646,0.697)\end{array}$ & $<0.001$ & $\begin{array}{l}-0.530 \\
(0.020)\end{array}$ & $\begin{array}{l}0.588 \\
(0.565,0.612)\end{array}$ & $<0.001$ \\
\hline $\begin{array}{l}\text { District: Central } \\
(n=2029)\end{array}$ & $\begin{array}{l}-0.035 \\
(0.053)\end{array}$ & $\begin{array}{l}0.965 \\
(0.869,1.071)\end{array}$ & 0.501 & $\begin{array}{l}-0.032 \\
(0.053)\end{array}$ & $\begin{array}{l}0.968 \\
(0.872,1.075)\end{array}$ & 0.544 \\
\hline $\begin{array}{l}\text { District: KaoPing } \\
(n=2388)\end{array}$ & $\begin{array}{l}-0.061 \\
(0.052)\end{array}$ & $\begin{array}{l}0.940 \\
(0.848,1.042)\end{array}$ & 0.240 & $\begin{array}{l}-0.090 \\
(0.052)\end{array}$ & $\begin{array}{l}0914 \\
(0.824,1.013)\end{array}$ & 0.086 \\
\hline $\begin{array}{l}\text { District: Northern } \\
(n=1301)\end{array}$ & $\begin{array}{l}0.064 \\
(0.055)\end{array}$ & $\begin{array}{l}1.067 \\
(0.956,1.190)\end{array}$ & 0.246 & $\begin{array}{l}-0.028 \\
(0.055)\end{array}$ & $\begin{array}{l}0.971 \\
(0.871,1.084)\end{array}$ & 0.604 \\
\hline $\begin{array}{l}\text { District: Southern } \\
(n=1695)\end{array}$ & $\begin{array}{l}-0.091 \\
(0.054)\end{array}$ & $\begin{array}{l}0.913 \\
(0.821,1.015)\end{array}$ & 0.091 & $\begin{array}{l}-0.119 \\
(0.054)\end{array}$ & $\begin{array}{l}0.887 \\
(0.798,0.987)\end{array}$ & 0.027 \\
\hline $\begin{array}{l}\text { District: Taipei } \\
(n=3090)\end{array}$ & $\begin{array}{l}0.001 \\
(0.051)\end{array}$ & $\begin{array}{l}1.001 \\
(0.905,1.107)\end{array}$ & 0.987 & $\begin{array}{l}-0.040 \\
(0.051)\end{array}$ & $\begin{array}{l}0.960 \\
(0.868,1.062)\end{array}$ & 0.429 \\
\hline
\end{tabular}

public hospitals and private clinics might improve the efficiency and timeliness of TB services in Taiwan [16].

Compared to our previous study [21], we further observed that patients with chronic respiratory diseases and those living in long-term care facilities have prolonged HSD. The non-specific nature of the symptoms of chronic respiratory diseases like cough is a risk factor associated with longer delays [25]. In addition, demographic changes have increased the number of elderly individuals for whom age-related immunosenescence may increase LTBI activation risk, especially in settings with vulnerable individuals [26]. A delayed diagnosis of TB in a long-term care facility may lead to nosocomial exposure [27]. Therefore, necessary resource allocation, like adoption of GeneXpert MTB/RIF in the health care system and testing by interferon-gamma release assay (IGRA) in longterm care facilities, might be considered [28].

HSD can be further divided into three interconnected components (Fig. 2): a) arousing suspicion time: the interval between the first medical consultation and the time when a TB diagnostic test is ordered; b) diagnosis time: the interval between ordering a TB diagnostic test and a positive result; c) treatment time: the interval between the positive diagnostic test and the initiation of TB treatment [29, 30]. According to the 2013 TB registry, we observed that the median delays for b) and c) were 5 and 0 days, respectively. Therefore, we estimated that the contribution of a) might be around 41 days (median) when matching patients' medical claims in the NHIRD.

Unlike Hanson et al.'s approach [31] using either a TB prevalence survey or demographic and health surveys to conduct PPA, our estimates of TB diagnosis and treatment access at the initial visit were obtained from the national $\mathrm{TB}$ registry and individual medical claims (NHIRD). While a TB prevalence survey provides TBspecific care-seeking data, the sample size of patients confirmed to have TB is usually small and will not allow for robust subnational analysis [31]. On the other hand, indicators from population-based demographic and health surveys are not TB-specific [31]. Our estimates from a total of 10,932 observations are not prone to small sample size and capture care-seeking pathways for patients with respiratory-related symptoms.

However, this study still has several limitations. Firstly, because one-fourth $(n=2848,26.1 \%)$ of the total observations from the $2013 \mathrm{~TB}$ registry lacked the treatment outcome information, we didn't include treatment outcomes in our study, which is important for a comprehensive PPA. Secondly, we only conducted a one-year retrospective study. The estimate of HSD and the share of access to $\mathrm{TB}$ diagnosis and treatment at the initial visit might be underestimated. In addition, the identification of chronic respiratory patients might be misclassified due to a short observation window (12 months), and a validation of the operational definition (28-day cutoff) 
is warranted. Finally, since being diagnosed with TB is a dynamic process, the percentage of access to TB diagnostic (treatment) services might be underestimated by comparing the date of initial visit (treatment initiation) in NHIRD and the date of TB diagnostic test (TB treatment) in the TB registry, which could be improved by reviewing the TB-related procedures from medical claims of NHIRD [30].

\section{Conclusions}

The low share of access to TB diagnostic and treatment services at the initial visit and the prolonged HSD indicate inefficiency in the health care system. Strengthening training of physicians at public hospitals and health workers at nursing homes might improve the efficiency and timeliness of $\mathrm{TB}$ diagnosis and treatment. In addition, we suggest that long-term care facilities and primary health care clinics might need to pay more attention on early identification of TB cases to avoid subsequent delays.

\section{Supplementary information}

Supplementary information accompanies this paper at https://doi.org/10. 1186/s12913-019-4702-0

Additional file 1: Table S1. Drug lists associated with chronic respiratory medicines

Additional file 2: Figure S1. Kaplan Meir plots (direct adjusted) for health system delay by risk factors

\section{Abbreviations}

Cl: Confidence interval; DOTS: Directly observed therapy, short-course; HRs: Hazard ratios; HSD: Health system delay; IGRA: Interferon-gamma release assay; IQR: Interquartile range; LTBI: Latent tuberculosis infection; NHIRD: National Health Insurance Research Database; PPA: Patient-pathway analysis; TB: Tuberculosis

\section{Acknowledgements}

We would like to express our sincere gratitude to Kent M. Suárez for his English editing.

\section{Authors' contributions}

TCC and YHC conceived the idea for the study design. CCC carried out the statistical analyses and wrote the first manuscript draft. PHC \& ICF helped interpret the results. TCC and $\mathrm{YHC}$ revised the manuscript and provided guidance on all issues related to the analysis. All authors contributed to the intellectual content and approved the final manuscript.

\section{Funding}

This research was supported by a grant titled "Multidisciplinary Health Cloud Research Program: Technology Development and Application of Big Health Data" from Academia Sinica and Taiwan CDC (MOHW106-CDC-114-000101). The funders had no role in study design, data collection and analysis, decision to publish, or preparation of the manuscript.

\section{Availability of data and materials}

The raw data are confidential and cannot readily be shared. Researcher need to obtain permission from the Institutional Review Board of their institutions and apply for access to the data from the Health and Welfare Data Science Center, Ministry of Health and Welfare, Taiwan.

\section{Ethics approval and consent to participate}

This study was approved by the institutional review board (IRB) of Kaohsiung Medical University Chung-Ho Memorial Hospital for research ethics (IRB\#: KMUHIRB-SV (I)-20160057). In addition, we applied the data from Health and Welfare Data Science Center, Ministry of Health and Welfare, Taiwan and got the permission for analyzing the data. The data used in this study were derived from linkage of two databases including the National Health Insurance Research Database (NHIRD) and the TB registry. The data were all analyzed anonymously. Therefore, we did not need to get consent from each patient.

Consent for publication

Not Applicable.

\section{Competing interests}

The authors declare that they have no competing interests.

\section{Author details}

${ }^{1}$ Center for Applied Artificial Intelligence Research, Soochow University, Taipei, Taiwan. ${ }^{2}$ Institute of Population Health Sciences, National Health Research Institutes, Zhunan, Taiwan. ${ }^{3}$ Department of Internal Medicine, Kaohsiung Municipal Ta-Tung Hospital, Kaohsiung, Taiwan. ${ }^{4}$ School of Medicine, Graduate Institute of Medicine, Sepsis Research Center, Center of Tropical Medicine and Infectious Diseases, Kaohsiung Medical University, Kaohsiung, Taiwan. ${ }^{5}$ Department of Biological Science and Technology, College of Biological Science and Technology, National Chiao Tung University, Hsin Chu, Taiwan. ${ }^{6}$ Institute of History and Philology, Academia Sinica, Taipei, Taiwan. ${ }^{7}$ Research Center for Humanities and Social Sciences, Academia Sinica, Taipei, Taiwan. ${ }^{8}$ Institute of Public Health, School of Medicine, National Yang-Ming University, Taipei, Taiwan. ${ }^{9}$ Division of Infectious Diseases, Department of Internal Medicine, Kaohsiung Medical University Hospital, Kaohsiung, Taiwan.

Received: 23 July 2018 Accepted: 31 October 2019

Published online: 19 November 2019

\section{References}

1. Chiang CY, Chang CT, Chang RE, Li CT, Huang RM. Patient and health system delays in the diagnosis and treatment of tuberculosis in southern Taiwan. Int J Tuberc Lung Dis. 2005;9(9):1006-12.

2. CDC: Statistics of communicable diseases and surveillance report 2016. Centers for disease control, Taiwan; 2017.

3. Chien JY, Lai CC, Tan CK, Chien ST, Yu CJ, Hsueh PR. Decline in rates of acquired multidrug-resistant tuberculosis after implementation of the directly observed therapy, short course (DOTS) and DOTS-plus programmes in Taiwan. J Antimicrob Chemother. 2013;68(8):1910-6.

4. Yen YF, Rodwell TC, Yen MY, Shih HC, Hu BS, Li LH, Shie YH, Chuang P, Garfein RS. DOT associated with reduced all-cause mortality among tuberculosis patients in Taipei, Taiwan, 2006-2008. Int J Tuberc Lung Dis. 2012;16(2):178-84.

5. Lin SY, Chiu YW, Lu PL, Hwang SJ, Chen TC, Hsieh MH, Chen YH. Three months of rifapentine and isoniazid for latent tuberculosis infection in hemodialysis patients: high rates of adverse events. J Microbiol Immunol Infect. 2018:52:158-62

6. Golub JE, Bur S, Cronin WA, Gange S, Baruch N, Comstock GW, Chaisson RE. Patient and health care system delays in pulmonary tuberculosis diagnosis in a low-incidence state. Int J Tuberc Lung Dis. 2005;9(9):992-8.

7. Pan SC, Chen CC, Chiang YT, Chang HY, Fang CT, Lin HH. Health care visits as a risk factor for tuberculosis in Taiwan: a population-based case-control study. Am J Public Health. 2016:106(7):1323-8.

8. Humphreys $\mathrm{H}$. Control and prevention of healthcare-associated tuberculosis: the role of respiratory isolation and personal respiratory protection. J Hosp Infect. 2007;66(1):1-5.

9. Fatima R, Haq MU, Yaqoob A, Mahmood N, Ahmad KL, Osberg M, Makayova J, Hymoff A, Hanson C. Delivering patient-centered care in a fragile state: using patient-pathway analysis to understand tuberculosis-related care seeking in Pakistan. J Infect Dis. 2017;216(suppl_7):S733-9.

10. Fekadu L, Hanson C, Osberg M, Makayova J, Mingkwan P, Chin D. Increasing access to tuberculosis services in Ethiopia: findings from a patient-pathway analysis. J Infect Dis. 2017;216(suppl_7):S696-701.

11. Garfin C, Mantala M, Yadav R, Hanson CL, Osberg M, Hymoff A, Makayova J. Using patient pathway analysis to design patient-centered referral networks 
for diagnosis and treatment of tuberculosis: the case of the Philippines. J Infect Dis. 2017;216(suppl_7):S740-7.

12. Masini E, Hanson C, Ogoro J, Brown J, Ngari F, Mingkwan P, Makayova J, Osberg M. Using patient-pathway analysis to inform a differentiated program response to tuberculosis: the case of Kenya. J Infect Dis. 2017; 216(suppl_7):S714-23.

13. Surya A, Setyaningsih B, Suryani Nasution H, Gita Parwati C, Yuzwar YE, Osberg M, Hanson CL, Hymoff A, Mingkwan P, Makayova J, et al. Quality tuberculosis care in Indonesia: using patient pathway analysis to optimize public-private collaboration. J Infect Dis. 2017;216(suppl_7):S724-32.

14. Tattevin P, Che D, Fraisse P, Gatey C, Guichard C, Antoine D, Paty MC Bouvet E. Factors associated with patient and health care system delay in the diagnosis of tuberculosis in France. Int J Tuberc Lung Dis. 2012;16(4): 510-5.

15. Diez M, Bleda MJ, Alcaide J, Castells C, Cardenal Jl, Dominguez A, Gayoso P, Guitierrez G, Huerta C, Lopez MJ, et al. Determinants of health system delay among confirmed tuberculosis cases in Spain. Eur J Pub Health. 2005;15(4): 343-9.

16. Chung WS, Chang RE, Guo HR. Variations of care quality for infectious pulmonary tuberculosis in Taiwan: a population based cohort study. BMC Public Health. 2007;7:107.

17. CDC: Taiwan guidelines for TB diagnosis \& treatment (6E). Centers for Disease Control, Taiwan; 2017.

18. Cheng CL, Kao YH, Lin SJ, Lee CH, Lai ML. Validation of the National Health Insurance Research Database with ischemic stroke cases in Taiwan. Pharmacoepidemiol Drug Saf. 2011;20(3):236-42.

19. Lee YC, Huang YT, Tsai YW, Huang SM, Kuo KN, McKee M, Nolte E. The impact of universal National Health Insurance on population health: the experience of Taiwan. BMC Health Serv Res. 2010;10:225.

20. Chiang CY: Integration of tuberculosis Services in Taiwan, 2001: challenges and opportunities. University of Bergen 2012.

21. Chen CC, Chiang CY, Pan SC, Wang JY, Lin HH. Health system delay among patients with tuberculosis in Taiwan: 2003-2010. BMC Infect Dis. 2015;15:491.

22. Katz MH, Hauck WW. Proportional hazards (cox) regression. J Gen Intern Med. 1993;8(12):702-11.

23. CDC: Taiwan tuberculosis control report 2014. Centers for disease control, Taiwan; 2015

24. Jurcev-Savicevic A, Mulic R, Kozul K, Ban B, Valic J, Bacun-Ivcek L, Gudelj I, Popijac-Cesar G, Marinovic-Dunatov S, Simunovic A. Health system delay in pulmonary tuberculosis treatment in a country with an intermediate burden of tuberculosis: a cross-sectional study. BMC Public Health. 2013;13:250.

25. Meyssonnier V, Li X, Shen X, Wang H, Li DY, Liu ZM, Liu G, Mei J, Gao Q. Factors associated with delayed tuberculosis diagnosis in China. Eur J Pub Health. 2013;23(2):253-7.

26. Harris TG, Sullivan Meissner J, Proops D. Delay in diagnosis leading to nosocomial transmission of tuberculosis at a New York City health care facility. Am J Infect Control. 2013;41(2):155-60.

27. Kelly AM, D'Agostino JF, Andrada LV, Liu J, Larson E. Delayed tuberculosis diagnosis and costs of contact investigations for hospital exposure: New York City, 2010-2014. Am J Infect Control. 2017;45(5):483-6.

28. Reddy D, Walker J, White LF, Brandeis GH, Russell ML, Horsburgh CR Jr Hochberg NS. Latent tuberculosis infection testing practices in long-term care facilities, Boston, Massachusetts. J Am Geriatr Soc. 2017;65(6):1145-51.

29. Lin HP, Deng CY, Chou P. Diagnosis and treatment delay among pulmonary tuberculosis patients identified using the Taiwan reporting enquiry system, 2002-2006. BMC Public Health. 2009;9:55.

30. Lee CH, Wang JY, Lin HC, Lin PY, Chang JH, Suk CW, Lee LN, Lan CC, Bai KJ. Treatment delay and fatal outcomes of pulmonary tuberculosis in advanced age: a retrospective nationwide cohort study. BMC Infect Dis. 2017;17(1):449.

31. Hanson CL, Osberg M, Brown J, Durham G, Chin DP. Conducting patientpathway analysis to inform programming of tuberculosis services: methods. J Infect Dis. 2017;216(suppl_7):S679-85.

\section{Publisher's Note}

Springer Nature remains neutral with regard to jurisdictional claims in published maps and institutional affiliations.

\section{Ready to submit your research? Choose BMC and benefit from:}

- fast, convenient online submission

- thorough peer review by experienced researchers in your field

- rapid publication on acceptance

- support for research data, including large and complex data types

- gold Open Access which fosters wider collaboration and increased citations

- maximum visibility for your research: over $100 \mathrm{M}$ website views per year

At BMC, research is always in progress.

Learn more biomedcentral.com/submissions 